\title{
CORRESPONDENCE
}

\section{Acceptance of peer review will free Italy's research slaves}

SIR - 'Italy must invest more in science and technology' according to I. Bertini, S. Garattini and R. Rappuoli in Correspondence (Nature 452, 685; 2008). They lament the Italian lack of financial resources and political attention for research, technology and education. As a researcher, clinician and academician, I share their concerns. However, as former chair of the health committee of the Italian Senate, I take exception to their implication that none of the major political parties recognizes science, technology and education as crucial for the future of the country's economy.

The 2007 and 2008 national budget laws, drawn up when the centre-left coalition was in power, allocated $€ 96$ million (US $\$ 149$ million) to projects submitted by researchers under 40 years old. These are judged by an international committee comprising ten scientists under 40 - five from foreign institutions - selected according to impact factor and citation index scores. This alone is a revolutionary approach for the unregulated Italian system of research funding allocation.

In spite of such advances, Italy is still far behind in research investment, and this needs to change. But the crucial switch is not simply to increase funding. The way the new government should proceed is to reform the allocation criteria for funding and to start applying across the board the selection and evaluation rules of peer review. Such a system would acknowledge meritocracy and free researchers from the virtual slavery under which they have been kept by old academicians.

By applying international rules of peer review and evaluating grant applications only on the basis of merit, looking at curricula and objectives, comparing lists of publications and evaluating results, we will provide opportunities for Italy's scientists, thereby promoting the country's intellectual, cultural and economic growth.

Ignazio R. Marino Department of Surgery, Jefferson Medical College, 19107 Philadelphia, Pennsylvania, USA, and Senate of the Republic of Italy, Piazza Madama snc, 00186 Rome, Italy

\section{Mimicking photosynthesis, but just the best bits}

SIR - Your News Feature 'The photon trap' (Nature 452, 400-402; 2008) makes good points about the challenges for converting solar to fuel energy by artificial photosynthesis. But we wish to clarify the assessment that "simply mimicking photosynthesis is too short-sighted".

The (highly optimistic) 3\% efficiency for solar energy conversion in plants covers everything that a plant gets up to, day and night, during an annual cycle. The whole complex process of photosynthesis, not to mention the plant's way of life, is certainly not a target for chemical mimicry. Biologically inspired chemistry based on photosynthesis focuses only on the specific reactions that are potentially useful.

Early aviation pioneers, who looked to birds for biomimetic aeroplane design features, incorporated wings, a tail, a fuselage and aspects of aerodynamics into their final product. In the main, they chose not to go for flapping - and nest-building and flying south for the winter were right out. Biomimetic chemistry is the same: we pick only the relevant bits.

The wateroxidizing enzyme you feature is currently the focus of attention - a chemical marvel in which a low-energy pathway removes electrons from water so that the enzyme can operate at minimum electrical over-potential. Its high energyconversion efficiency is unmatched by artificial catalysts derived from cheap and abundant elements.

Your News Feature implies that research on this enzyme has advanced to the point where it can provide a legitimate target for catalyst-hunting chemists to mimic. This is true, but there is still a good deal to be learned about the structure and mechanism of the enzyme itself and this will doubtless be of great benefit to future research on artificial photosynthesis.

A. William Rutherford iBiTEC-S, URA
2096 CNRS, CEA Saclay, 91191 Gif-surYvette, France

Thomas A. Moore Center for Bioenergy and Photosynthesis, Department of Chemistry and Biochemistry, Arizona State University, Tempe, Arizona 85287-1604, USA

Standard identifier could mobilize data and free time

SIR - The rise of bioinformatics has focused attention on the growing depth and scope of database content. However, it is difficult or impossible given the existing citation metrics system to identify who originally created or added value to a datum. Without a system to reward, we shall continue to rely on the good will
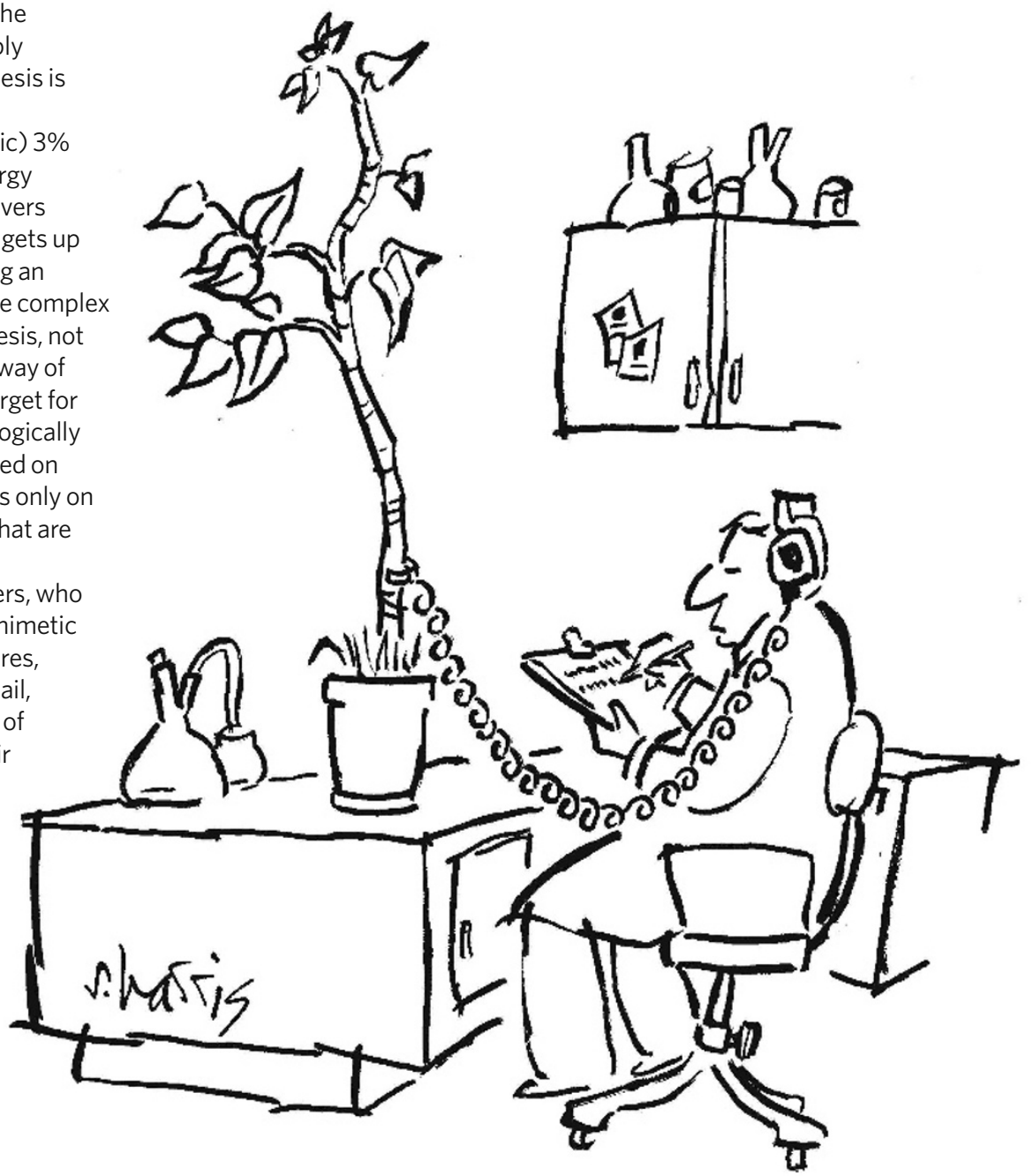